\title{
Effects of ICT-Based Multicomponent Program on Body Composition and Cognitive Function in Older Adults: A Randomized Controlled Clinical Study
}

\author{
Du-Ri Kim, ${ }^{1,2, *}$ \\ Seunghwan Song, (D) 1,3,* Gwon- \\ Min Kim, (D) ' Jae Hyeok Chang, 1,4 \\ Young Jin Tak, ${ }^{5}$ Up Huh, (D) ${ }^{1,3}$ \\ Jeong Su Cho, (iD) ${ }^{3}$ Yung Liao, (iD) ${ }^{6}$ \\ Kap-Soo Han, ${ }^{7}$ Myoung- \\ Hwan Ko, (D) ${ }^{7,8}$ Jong-Hwan Park (D) ${ }^{\prime}$ \\ 'Health Convergence Medicine Laboratory, \\ Biomedical Research Institute, Pusan National \\ University Hospital, Busan, Korea; ' 2 Department of \\ Occupational Therapy, Graduate School of Inje \\ University, Gimhae, Korea; ${ }^{3}$ Department of \\ Thoracic and Cardiovascular Surgery, School of \\ Medicine, Pusan National University, Department \\ of Thoracic and Cardiovascular Surgery, Pusan \\ National University Hospital, Busan, Korea; \\ ${ }^{4}$ Department of Rehabilitation Medicine, School of \\ Medicine, Pusan National University, Department \\ of Rehabilitation Medicine, Pusan National \\ University Hospital, Busan, Korea; ${ }^{5}$ Department of \\ Family Medicine, Pusan National University \\ Hospital, Busan, Korea; ${ }^{6}$ Department of Health \\ Promotion and Health Education, National Taiwan \\ Normal University, Taipei, Taiwan; ${ }^{7}$ Research \\ Institute of Clinical Medicine of Jeonbuk National \\ University-Biomedical Research Institute of \\ Jeonbuk National University Hospital, Jeonju, \\ Korea; ${ }^{8}$ Department of Physical Medicine and \\ Rehabilitation, Jeonbuk National University \\ Medical School, Jeonju, Korea \\ *These authors contributed equally to this work
}

Correspondence: Myoung-Hwan Ko Department of Physical Medicine and Rehabilitation, Jeonbuk National University Medical School, 20 Geonji-ro,

Deokjin-gu, Jeonju, 54907, Korea

Tel +82-63-250-I 785

Email mhko@jbnu.ac.kr

Jong-Hwan Park

Health Convergence Medicine Laboratory, Biomedical Research Institute, Pusan National University Hospital, 179, Gudeok-Ro, Seo-Gu,

Busan, 4924I, Korea

Tel +82-5 I-240-707I

Email parkj@pusan.ac.kr
Purpose: Information and communication technology (ICT)-based training devices for older adults' care related to dementia are being developed to enhance older adults' cognitive functions. Older adults who require bicycle training devices can improve muscle strength and balance of lower limbs by continuously contracting and relaxing lower-limb muscles and improving cognitive function to prevent dementia. This study was conducted to investigate the effects of an ICT-based multicomponent program on body composition and cognitive function in older adults.

Patients and Methods: In a randomized controlled intervention test on 20 people over the age of 60 (exercise group: $n=10$; control: $n=10$ ), the multicomponent program was applied to the exercise group twice per week, once per day for 12 weeks, at 30 min per session, whereas the control group was advised to maintain their usual daily activities.

Results: Comparing body composition changes and cognitive function changes before and after intervention exhibited statistically significant differences in skeletal muscle mass $(P=0.01)$ and modified Alzheimer's disease assessment scale-cognitive score $(P=0.01)$ between the two groups.

Conclusion: It can be difficult to be engaged in a simple repetitive exercise program. Therefore, to meet older adults' interests and expectations, a customized ICT-based multicomponent program, which can improve body composition and cognitive function in older adults and is believed to help prevent dementia, is recommended.

Trial Registration: UMIN000042129 (https://www.umin.ac.jp/english/).

Keywords: ICT-based multicomponent program, body composition, cognitive function, dementia, older adults

\section{Introduction}

The number of older people representing South Korea's population increases, with older adults aged 65 or older constituting $15.7 \%$ of the national total. The number of older adults is expected to rise to 13 million, equivalent to $20.3 \%$ by 2025 and $25.0 \%$ by $2030 .{ }^{1}$ The aging population has led to a surge in pathologic aging, one of which is dementia, which causes difficulties in performing daily activities owing to decreased cognitive function and physical activity, among other neurobehavioral symptoms. Therefore, the prevention of these diseases through exercise is of paramount importance. ${ }^{2}$ A recent study has shown that exercise leads to the hippocampus's neurogenesis and helps with memory and learning, thus improving brain aging and cognitive function. ${ }^{3}$ Additionally, exercise improves physical health 
and function by increasing flexibility and physical activity, and balance, reducing depression and preventing pathologic aging. ${ }^{4}$

According to previous studies on exercises, physical function, and cognitive functions, aerobic exercises, including cycling, have been reported to significantly increase volumes of white matter in the anterior and frontal lobes, thereby expanding the hippocampus's size and improving memory. ${ }^{5}$ Additionally, aerobic exercise significantly correlates with brain-derived neurotrophic factor changes, positively affecting cognitive function. ${ }^{6,7}$ In one study, after 24 weeks of a multicomponent exercise intervention on older adults with dementia, physical function measures, such as lower-limb muscle strength, brachialmuscle strength, lower-limb flexibility, balance, dynamic balance, and mobility, improved significantly. ${ }^{8}$ Physical strength has been proved to enhance morphological changes in the brain by promoting cardiovascular and neurotransmitter functions that maintain or improve cognitive function. ${ }^{9}$

Furthermore, lower-limb muscle strengthening and balance-ability exercises are essential to reduce the risk of fractures caused by falls among older adults. In contrast, upper-limb exercises for the shoulder, arm, and torso are necessary to improve flexibility. ${ }^{10,11}$ Although older adults have more time and training opportunities than other age groups, they tend to be inactive and passive toward practice, ${ }^{12}$ resulting in low actual exercise rates. ${ }^{13}$ Furthermore, simple repetitive exercise programs fail to engage older adults to exercise continuously because these programs do not induce their interest or meet their expectations. ${ }^{14}$

A multi-intervention program is a technique that combines two or more non-drug treatment methods reported to be effective in physical, cognitive, and psychosocial aspects, ${ }^{15}$ including cognitive, emotional, physical, musical, artistic, and sensory functions. Such a program stimulates interest and encourages participation better than implementing a simple intervention program. ${ }^{8,16}$ In previous studies conducted on older adults, multi-intervention programs effectively improved physical function measures, such as dynamic balance, and enhanced cognitive function. ${ }^{17}$ In particular, multi-intervention programs focused on physical exercise and cognitive and social activities helped maintain cognitive functions among dementia patient groups. ${ }^{18}$ Moreover, when applied to older adults who had suffered from strokes, these programs improved upper-limb and balance functions. They were effective at promoting cognitive function and reducing depression. ${ }^{19}$ Accordingly, the application of these programs positively affects physical function and cognitive function and reduces depression in older adults.

However, with recent information and communication technology (ICT) developments, such as the Internet of Things and virtual reality (VR), the expansion of the u-healthcare market has led to increased product development and the creation of a need for improving wellness and physical rehabilitation activities in the concept of a personal trainer. However, the undiscerning commercialization of products with insufficiently proven clinical effects on rehabilitation continues to increase. ${ }^{20}$ Meanwhile, based on ICT R\&D and active and healthy aging program to tackle the challenges and seize the opportunities of demographic change, ICT-based training devices for older adults' care related to dementia are being developed to enhance the cognitive functions of older adults. For older adults who require lower-limb exercise, bicycle training devices can improve muscle strength and balance by continuously contracting and relaxing lowerlimb muscles ${ }^{21}$ and improve cognitive function to help prevent dementia. In particular, VR is a tool that allows subjects to entirely imitate an actual situation, which is rich in cognitive and physical function. ${ }^{22}$

Consequently, this study was conducted to evaluate the effects of applying a multicomponent program using ICTbased bicycles customized for older adults on their body compositions and cognitive functions. Additionally, as it can be challenging to encourage the older adults to exercise using only a simple repetitive exercise program continuously, a multicomponent program was applied to induce the older adults' interest and meet their expectations.

\section{Materials and Methods Study Design and Participants}

A total of 20 individuals were recruited through a notice from Pusan National University Hospital. All participants provided their voluntary consent to participate after receiving a detailed explanation of the study's purpose and methods. The inclusion criteria were as follows: (1) males and females at least 60 years of age, (2) can read and write, (3) have no limitations that prevent them from performing their activities in daily life, and (4) do not have any regular (ie, more than twice a week) exercise habits. The exclusion criteria were as follows: (1) other general conditions 
associated with dementia, such as, but not limited to, hypothyroidism, vitamin B12 or folate deficiency, niacin deficiency, hyperkalemia, neurosyphilis, and human immunodeficiency virus, (2) major psychiatric disorders, such as, but not limited to, schizophrenia, delusional disorders, bipolar disorder, and alcohol and/or substance abuse disorders, as diagnosed according to the DSM-5 diagnostic criteria, (3) difficulties that hamper assessment, eg, due to visual and hearing impairments, (4) cardiovascular diseases, neurological diseases, unstable medical conditions, and other similar health disorders, and/or (5) ineligibility of the individual to participate in the trial for different reasons, as assessed by the principal investigator. The 20 participants were randomly assigned each group. The block randomization method was used to distribute the participants between an exercise group $(n=10)$ and control group $(n=10)$. The exercise group received an ICT-based multicomponent program once (30 min) a day, two days per week for 12 weeks, whereas the control group was advised to maintain their everyday activities. Our study was conducted following the Declaration of Helsinki of 1975 and its subsequent revisions. Ethical approval was obtained from the Institutional Review Board of Pusan National University Hospital (IRB No. H-1905-033-079). All participants provided written informed consent before enrollment.

\section{ICT-Based Multicomponent Program}

The ICT-based multicomponent program used in this study trains both physical and cognitive functions. It includes both a cognitive program and a VR bicycle riding program through Google Maps (Figure 1).

The VR bicycle device improves not just the lowerlimb muscles but also memory through VR and Google Maps and allows riders to reminisce and recall places relevant to their memories by cycling anywhere in and out of the country. Further, the device is equipped with handles to prevent older adults from falling and ride safely. In this study, bicycle riding was performed at average speeds greater than $3.5 \mathrm{~km} / \mathrm{h}$ for the $1 \mathrm{st}-6$ th weeks and $4.0 \mathrm{~km} / \mathrm{h}$ for the $7 \mathrm{th}-12 \mathrm{th}$ weeks.

Meanwhile, the cognitive program consists of training in arithmetic operations, fruit picking, and puzzle-solving. The arithmetic-operation exercise improves attention and calculation ability through activities where the participants match addition and subtraction expressions with their correct answers. The fruit-picking training improves concentration and reaction speed through activities where the participants pick fruits and put them into boxes. The puzzle-solving exercise improves execution abilities that require problemsolving skills and high-level cognitive functions through activities where the participants match puzzle pieces. All cognitive programs improve upper-limb muscle strength and cognitive function, measured using motion-recognition sensors on the moving upper extremities. Each training area was designed with three levels: easy, intermediate, and challenging. Therefore, training sessions can be adjusted to suit the condition of an individual.

\section{Research Procedures \\ Body Composition Assessment}

Body composition in terms of weight $(\mathrm{kg})$, body mass index $\left(\mathrm{kg} / \mathrm{m}^{2}\right)$, fat $(\%)$, and skeletal muscle mass $(\mathrm{kg})$ was measured using the Inbody 120 system (Inbody 120, Inbody, South Korea).

\section{Physical Function Assessment}

\section{Short Physical Performance Battery (SPPB)}

The SPPB series of tests, which was developed by Guralnik et $\mathrm{al}^{23}$ was performed in the following sequence: a) standing-balance tests, b) 4-m gait-speed test, and c) repeated-chair-stand test.

In the standing-balance test, the participants were asked to remain standing with their feet as close together as possible, and subsequently in a semi-tandem position (ankle of one foot behind the joint of the other foot), followed by a tandem position (ankle of one foot directly behind the other foot and touching it). Each position had to be held for $10 \mathrm{~s}$. The scores ranged from 0 (worst performance) to 4 (best performance).

In the gait-speed test, the time required for each participant to travel $4 \mathrm{~m}$ at an average pace was measured. This test was repeated twice, and the analysis used the shorter time of the two measured values.

In the repeated-chair-stand test, the participants were required to rise from a chair five times while their arms were across their chests. Each test was scored from 0 (worst performance) to 4 (best performance).

The standing-balancing test was evaluated according to a hierarchical combination of the performance of the three phases of the test (ie, feet close together, semitandem position, and tandem position). However, for the other two tests, a score of 0 was assigned to participants who did not (or could not) complete or attempt the task, and scores of 1-4 were assigned based on the time spent to perform each task. Lastly, the entire battery test's total score was obtained as the sum of all three tests; 


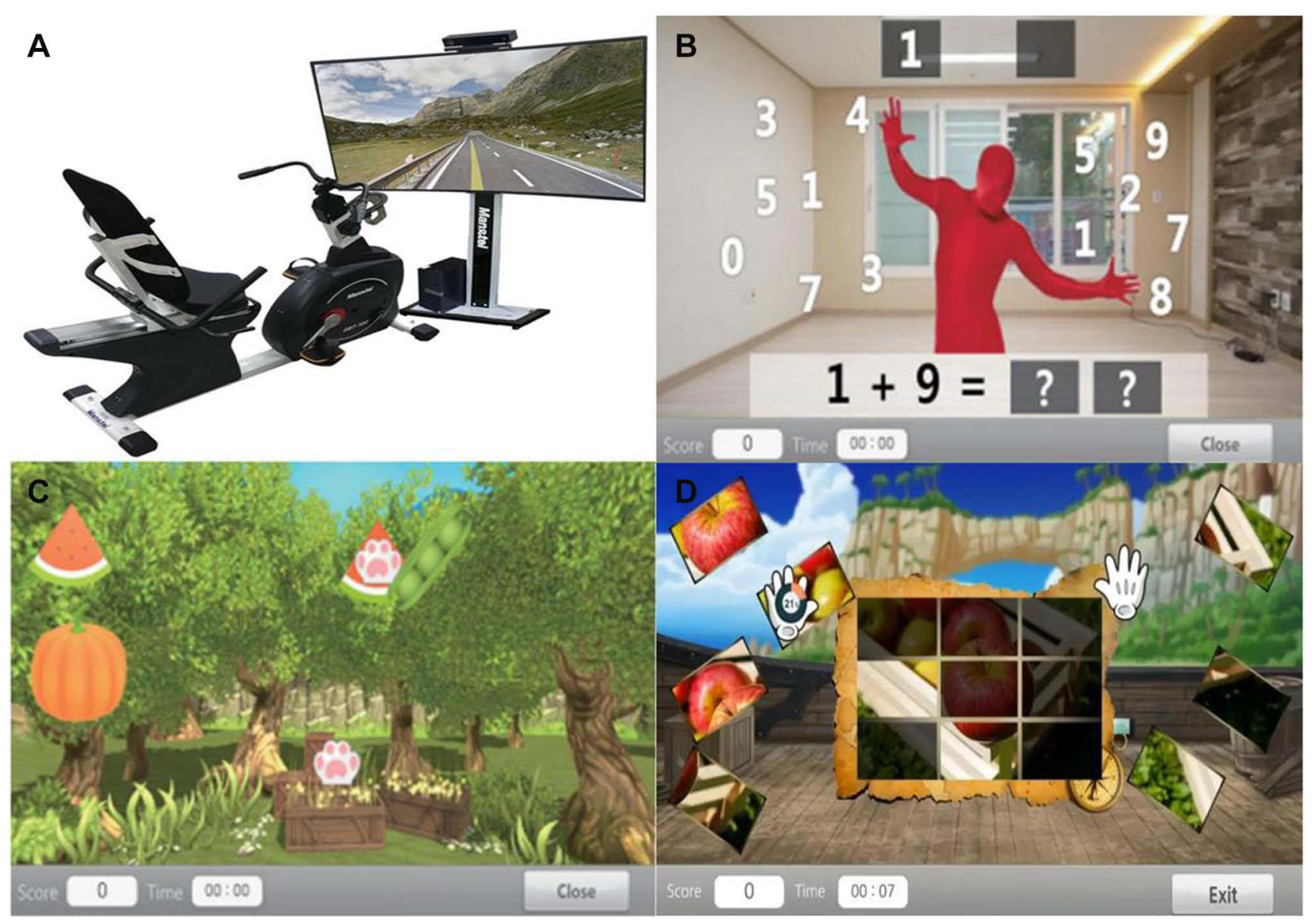

Figure I Information and communication technology (ICT)-based multicomponent program. (A) ICT-based bicycle. (B) Arithmetic-operation training. (C) Fruit-picking training. (D) Puzzle-solving training.

this total score varied between 0 (worst performance) and 12 (best performance). Participants were divided into three groups by SPPB score: 0 (unable to perform SPPB), 1-6 (low performance), and 7-12 (high performance).

\section{Timed Up and Go (TUG)}

The TUG test, which measures the functional mobility and dynamic balance of the older adults, was developed by Podsiadlo and Richardson ${ }^{24}$ to predict the risk of falls of a person. For this test, an armchair seat with a height of $46 \mathrm{~cm}$ and a mark on the floor $3 \mathrm{~m}$ away from the chair was used. After being provided with verbal instructions, the participants performed one trial of the TUG. Each participant stood up from the chair, walked to the mark $3 \mathrm{~m}$ away, turned around, returned to the chair, and sat down again. Participants walked safely but as fast as possible. The time from standing up to sitting down again was measured, with a time greater than $10 \mathrm{~s}$ categorized as abnormal.

\section{Grip-Strength Test}

Each participant's grip strength was measured using a digital grip-strength dynamometer (T.K.K. 5401; Takei, Niigata, Japan). Grip strength was measured in the standing position with the forearm away from the body at the thigh-level. Grip strengths for both hands were measured alternately twice, totaling four measurements, with $30 \mathrm{~s}$ of rest between measurements. The maximum value among these measurements was considered as the final grip strength.

\section{Cognitive Function Assessment}

Modified Alzheimer's Disease Assessment ScaleCognitive Subscale (ADAS-Cog)

The modified ADAS-Cog test, which was developed by Rosen et $\mathrm{al}^{25}$ consists of the following tasks (and their respective scoring ranges, with higher scores indicating worse performance in the test): Word Recall (0-12), Commands (0-5), Constructional Praxis (0-5), Word 
Delayed Recall (0-12), Naming Objects/Fingers (0-5), Ideational Praxis (0-5), Orientation (0-8), Word Recognition (0-12), Remembering Instructions (0-5), Spoken Language Ability (0-5), Word Finding Difficulty $(0-5)$, Comprehension $(0-5)$, and Distractibility $(0-5)$. The test's total score ranges from 0 to 89 , with higher scores indicating greater cognitive impairment severity.

\section{Korean Mini-Mental State Examination (K-MMSE)}

The cognitive function of each participant was examined using the Korean version of the MMSE (K-MMSE), ${ }^{26}$ adapted from Folstein et $\mathrm{al}^{27}$. The K-MMSE is the most commonly used screening test in South Korea. It includes items assessing orientation ( 5 points each for time orientation and place orientation), memory (3 points each for immediate recall and delayed recall), attention, and serial subtraction ( 5 points), language ability ( 2 points for naming, 3 points for oral command comprehension, 1 point each for repetition, reading, and writing), and visuospatial ability (1 point), where higher scores indicate higher cognitive function. The maximum score for the entire test is 30 .

\section{Digit Span Test (DST): Forward and Backward}

The DST, which is included in the Korean version of the Wechsler Adult Intelligence Scale (K-WAIS), ${ }^{28}$ is a numerical memorization test used to assess memory span and attention toward auditory stimuli. It is not considerably affected by age, education, or intelligence. The "forward" stimuli consist of numbers with lengths ranging from 3 to 9 digits, whereas the "backward" stimuli consist of numbers with sizes ranging from 2 to 8 digits. During the test, numbers were read to the participant at a rate of one digit per second, up to the last set of numbers. If the participant committed two consecutive errors, the forward test was stopped, commencing the backward test.

\section{Controlled Oral Word Association Test (COWAT)}

The COWAT scores of the participants were evaluated using the Korean version of the COWAT $^{29}$ (Benton developed the original version of the test in 1968). ${ }^{30}$ The measure involves semantic (category) and phonemic (letter) word fluency tests. In the semantic (animal) word fluency test, the participants were required to generate names of as many animals as possible in $60 \mathrm{~s}$. Meanwhile, in the phonemic (letter) word fluency test, the participants were asked to list as many words as possible that begin with a given letter; for example, the letter " $\neg$." Three 1-min trials, each for a different letter (eg, $\neg, \circ, \curlywedge)$, were administered. The score for each letter was the total number of admissible words for that letter.

\section{Digit Symbol Coding (DSC)}

For this experiment, the DSC test modified by Kang et $\mathrm{al}^{31}$ was implemented. This task involves rows containing small blank squares, each paired with a randomly assigned number from 1 to 9 . Above these rows is a printed key that pairs each number with a different symbol. The examinee had $120 \mathrm{~s}$ to pair specific numbers with their corresponding geometric figures using a reference key. Scaled scores were obtained for this test.

\section{Korean Color-Word Stroop Test (K-CWST)}

The Stroop test measures inhibitory function, cognitive control, response flexibility, and selective attention from among the frontal lobe's executive functions. In this experiment, the frontal-lobe executive function was assessed using the Korean version of the CWST (K-CWST). ${ }^{31}$ The test can be broadly divided into two forms: word reading and color reading. In the Stroop word-reading test, 112 words were presented in color, and the participant was required to read the words rather than the colors in which they were printed. In contrast, in the Stroop color-reading test, if the word "blue," for example, is printed in red ink, the participant was supposed to say "red" (ie, the color) instead of "blue" (ie, the word). In each test, the participant was given $2 \mathrm{~min}$ (120 s) to read as many words (or colors, whichever was required) as possible, and the number of words (or colors) read correctly was counted.

\section{Depression Function Test}

Symptoms of depression in the participants were evaluated using the short-form geriatric depression scale: Korean version (SGDS-K), ${ }^{32}$ which is a reduced version of the geriatric depression scale developed by Yesavage et $\mathrm{al}^{33}$. The shortform measurement method consists of 15 short questions about the participants' feelings from the previous week. Each question can be answered with a simple "Yes" (1 point) or "No" ( 0 points). The total score ranges from $0-15$ and is classified as either normal (0-5), mild depression (69), or severe depression (10-15). A higher SGDS-K score indicates more severe depression.

\section{Subjective Evaluation of Cognitive Function}

This evaluation was based on the following six categories: memory, orientation, visuospatial, attention, executive 
function, and language function. For each item in the questionnaire, the participants were asked to identify exactly one selection from the following 7-point scale: "very much (1 point)," "very much better ( 2 points)," "a little bit better (3 points), " "no change (4 points)," "very bad (5 points)," "a lot worse (6 points)," or "much worse (7 points)." The total score ranged from 6 to 42 points. A higher score indicates a worse change in the cognitive function of the participant.

\section{Statistical Analysis}

The data were analyzed using IBM SPSS ver. 22.0 (IBM Corp., Armonk, USA). This study has shown a non-normal distribution as a small sample size. All data have expressed as mean \pm standard deviation. The general characteristics of the participants have analyzed using the independent $t$-test. The Mann-Whitney $U$-test has used to compare the participants' conditions in independent groups. The two-way repeated-measures analysis of variance (ANOVA) was used to determine the mean difference concerning time-by-group. For all tests, statistical significance was set at $P<0.05$.

\section{Results}

\section{Characteristics of Participants}

A total of 20 participants (control group $=10$, exercise group $=10$ ) were involved in this study. The control group was composed of one male and nine females of mean age $64.70 \pm 6.83$ years, whereas the exercise group was composed of two males and eight females of mean age $68.32 \pm 6.32$ years. The mean education levels were $9 \pm 4$ years for the control group and $7 \pm 3$ years for the exercise group. When asked if they were currently smoking, $0(0 \%)$ participants from both the control and exercise groups responded "yes." When asked if they were presently drinking alcohol, $3(30 \%)$ respondents from the control group, and $4(40 \%)$ from the exercise group responded "yes." The mean systolic blood pressure was $135.70 \pm 15.24 \mathrm{mmHg}$ for the control group and $117.75 \pm 17.58 \mathrm{mmHg}$ for the exercise group, whereas the mean diastolic blood pressure was $81.55 \pm 9.80 \mathrm{mmHg}$ for the control group and $69.35 \pm 11.19$ $\mathrm{mmHg}$ for the exercise group. The mean height was $158.05 \pm 7.00 \mathrm{~cm}$ for the control group and 156.69 $\pm 4.10 \mathrm{~cm}$ for the exercise group, whereas the mean weight was $54.88 \pm 7.51 \mathrm{~kg}$ for the control group and 63.21 $\pm 7.16 \mathrm{~kg}$ for the exercise group. The mean body mass index was $21.98 \pm 2.70 \mathrm{~kg} / \mathrm{m}^{2}$ for the control group and $25.34 \pm 2.90 \mathrm{~kg} / \mathrm{m}^{2}$ for the exercise group. The skeletal muscle mass was $20.56 \pm 2.67 \mathrm{~kg}$ for the control group and $20.90 \pm 2.30 \mathrm{~kg}$ for the exercise group, whereas the fat mass percentage was $30.82 \pm 6.81 \%$ for the control group and $37.66 \pm 6.65 \%$ for the exercise group. (Table 1)

\section{Changes in Body Composition and Physical Function}

After the program was implemented, statistically significant differences in skeletal muscle mass were observed between the control and exercise groups: skeletal muscle

Table I Baseline Characteristics in Terms of Socio-Demographic and Physical Characteristics

\begin{tabular}{|c|c|c|c|}
\hline & \multicolumn{2}{|c|}{ Group } & \multirow[b]{2}{*}{$\boldsymbol{P}$} \\
\hline & Control $(n=10)$ & Exercise $(n=10)$ & \\
\hline \multicolumn{4}{|l|}{ Socio-demographic } \\
\hline Age (year) & $64.70 \pm 6.83$ & $68.32 \pm 6.32$ & $0.4 \mathrm{I}$ \\
\hline Male, n (\%) & I (10\%) & $2(20 \%)$ & 0.14 \\
\hline Education level (year) & $9 \pm 4$ & $7 \pm 3$ & 0.45 \\
\hline Smoking, n (\%) & $0(0 \%)$ & $0(0 \%)$ & - \\
\hline Alcohol drinking, n (\%) & $3(30 \%)$ & $4(40 \%)$ & 0.66 \\
\hline Systolic blood pressure $(\mathrm{mmHg})$ & $135.70 \pm 15.24$ & $117.75 \pm 17.58$ & 0.25 \\
\hline Diastolic blood pressure $(\mathrm{mmHg})$ & $81.55 \pm 9.80$ & $69.35 \pm 11.19$ & 0.19 \\
\hline \multicolumn{4}{|l|}{ Physical characteristics } \\
\hline Height $(\mathrm{cm})$ & $158.05 \pm 7.00$ & $156.69 \pm 4.10$ & 0.60 \\
\hline Weight $(\mathrm{kg})$ & $54.88 \pm 7.51$ & $62.21 \pm 7.16$ & $0.04 *$ \\
\hline Body mass index $\left(\mathrm{kg} / \mathrm{m}^{2}\right)$ & $21.98 \pm 2.70$ & $25.34 \pm 2.90$ & $0.02^{*}$ \\
\hline Skeletal muscle mass $(\mathrm{kg})$ & $20.56 \pm 2.67$ & $20.90 \pm 2.30$ & 0.76 \\
\hline Fat mass $(\%)$ & $30.82 \pm 6.81$ & $37.66 \pm 6.65$ & $0.04 *$ \\
\hline
\end{tabular}

Notes: Values are in terms of mean \pm SD. $*$ Significantly different from group: $P<0.05$. 
mass $(\mathrm{kg})$ decreased from $20.56 \pm 2.67$ to $20.44 \pm 2.53$ for the control group and improved from $20.90 \pm 2.30$ to 21.35 \pm 2.33 for the exercise group (Figure 2). However, no statistically significant differences were exhibited for fat percentage $(\%)$, which decreased from $30.82 \pm 6.81$ to $30.34 \pm 6.65$ and from $37.66 \pm 6.65$ to $36.04 \pm 6.71$ for the control and exercise groups, respectively.

No statistically significant differences were measured for the SPPB (score), which decreased from $12.00 \pm 0.00$ to $11.80 \pm 0.63$ for the control group and improved from 11.50 \pm 0.85 to $11.80 \pm 0.63$ for the exercise group. Similarly, no statistically significant differences were demonstrated for the TUG (s), which decreased from $5.87 \pm 1.03$ to 5.80 \pm 0.91 and from $6.02 \pm 1.12$ to $5.79 \pm 0.94$ for the control and exercise groups, respectively.

No statistically significant differences were observed for the right grip strength $(\mathrm{kg})$, which improved from $23.02 \pm 3.29$ to $23.10 \pm 3.87$ and from $24.04 \pm 5.49$ to 24.20 \pm 5.86 for the control and exercise groups, respectively, and for the left grip strength $(\mathrm{kg})$, which decreased from 20.41 \pm 3.33 to $20.38 \pm 3.51$ and from $21.83 \pm 5.93$ to $21.62 \pm 7.63$ for the control and exercise groups, respectively (Table 2).

\section{Changes in Cognitive Function}

Statistically significant differences were measured for the ADAS-Cog score, which decreased from 13.10 \pm 3.70 to $12.80 \pm 4.37$ for the control group and from $14.70 \pm 5.01$ to $10.20 \pm 4.05$ for the exercise group (Figure 3). Moreover, no statistically significant differences were exhibited for the K-MMSE score, which improved from $26.80 \pm 1.69$ to

\section{Skeletal muscle mass}

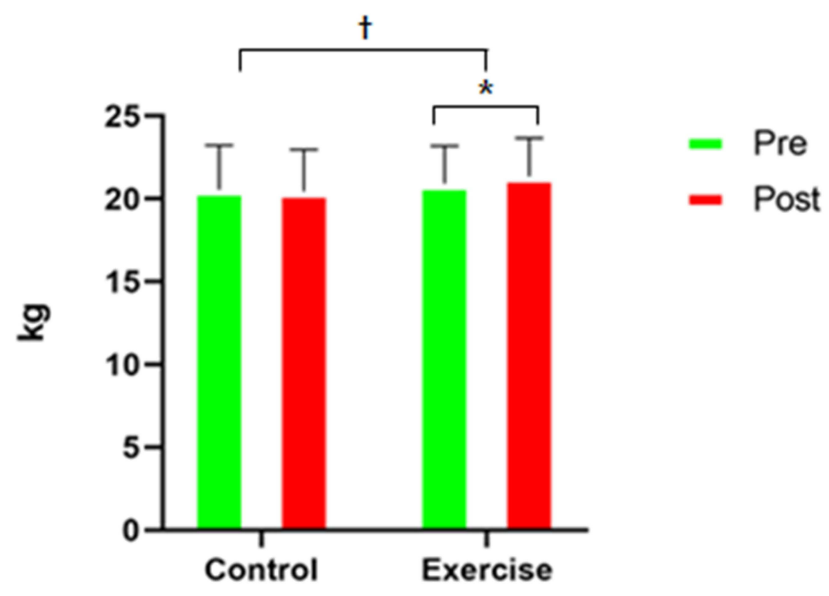

Figure 2 Changes in modified skeletal muscle mass at 12 weeks between control and exercise groups. *Significant difference between pre-intervention and postintervention $(P<.05)$; †Significant difference between time-by-group $(P<.05)$.
$27.00 \pm 2.31$ and from $26.30 \pm 2.11$ to $26.50 \pm 2.32$ for the control and exercise groups, respectively.

Furthermore, no statistically significant differences were observed for the DST score (for both forward and backward tests), which decreased from $10.00 \pm 2.40$ to 9.60 \pm 2.72 for the control group and from $9.60 \pm 2.01$ to 9.30 \pm 2.79 for the exercise group. Similarly, no statistically significant differences were demonstrated for the COWAT animal score, which improved from $15.30 \pm 3.43$ to $15.50 \pm 4.12$ for the control group and decreased from $14.60 \pm 3.44$ to $12.80 \pm 3.82$ for the exercise group, and for the COWAT $\neg+0+\lambda$ score, which improved from 26.60 \pm 9.82 to $31.10 \pm 13.25$ for the control group and improved from $21.90 \pm 7.40$ to $25.20 \pm 7.44$ for the exercise group. No statistically significant differences were calculated for the DSC score, which improved from $49.70 \pm 18.04$ to 53.40 \pm 20.72 and from $39.20 \pm 11.75$ to $43.50 \pm 14.01$ for the control and exercise groups, respectively.

Moreover, no statistically significant differences were measured for the word Stroop test scores, which decreased from $110.80 \pm 1.69$ to $109.70 \pm 5.58$ for the control group and from $111.30 \pm 1.34$ to $111.00 \pm 2.31$ for the exercise group. Similarly, no statistically significant differences were measured for the color Stroop test scores, which improved from $95.70 \pm 22.16$ to $96.80 \pm 22.63$ for the control group and decreased from $94.00 \pm 17.49$ to $93.70 \pm 22.35$ for the exercise group. No statistically significant differences were observed for the SGDS-K score, which decreased from $2.90 \pm 2.42$ to $2.00 \pm 2.75$ for the control group and from $3.80 \pm 3.19$ to $2.60 \pm 3.27$ for the exercise group (Table 3).

\section{Subjective Cognitive Function}

A questionnaire assessment was conducted to identify subjective cognitive function changes after 12 weeks between the control and exercise groups. The results showed that the average score was 15.5 for the exercise group and 21.8 for the control group. Compared to the control group, which was allowed to maintain their daily activities, the exercise group felt that their cognitive functions had improved after applying for the ICT-based multicomponent program.

\section{Discussion}

This study examined the effects of an ICT-based multicomponent program on older adults' body composition and cognitive function by conducting the program twice a week for 12 weeks at 30 min per session. According to 
Table 2 Changes in Body Composition Measurements and Physical Functions at Baseline and After 12 Weeks for Exercise and Control Groups

\begin{tabular}{|c|c|c|c|c|c|}
\hline Variables & Group & Pre & Post & \%diff & $P$ \\
\hline Weight (kg) & $\begin{array}{l}\text { Control } \\
\text { Exercise }\end{array}$ & $\begin{array}{l}54.88 \pm 7.51 \\
62.21 \pm 7.16\end{array}$ & $\begin{array}{l}55.52 \pm 7.50 \\
62.62 \pm 6.79\end{array}$ & $\begin{array}{l}1.17 \\
0.66\end{array}$ & 0.58 \\
\hline Body mass index $\left(\mathrm{kg} / \mathrm{m}^{2}\right)$ & $\begin{array}{l}\text { Control } \\
\text { Exercise }\end{array}$ & $\begin{array}{l}21.98 \pm 2.70 \\
25.34 \pm 2.90\end{array}$ & $\begin{array}{l}22.19 \pm 2.63 \\
25.53 \pm 2.86\end{array}$ & $\begin{array}{l}0.96 \\
0.77\end{array}$ & 0.92 \\
\hline Skeletal muscle mass $(\mathrm{kg})$ & $\begin{array}{l}\text { Control } \\
\text { Exercise }\end{array}$ & $\begin{array}{l}20.56 \pm 2.67 \\
20.90 \pm 2.30\end{array}$ & $\begin{array}{l}20.44 \pm 2.53 \\
21.35 \pm 2.33\end{array}$ & $\begin{array}{l}-0.58 \\
2.15^{*}\end{array}$ & $0.01 \dagger$ \\
\hline$\%$ fat (\%) & $\begin{array}{l}\text { Control } \\
\text { Exercise }\end{array}$ & $\begin{array}{l}30.82 \pm 6.81 \\
37.66 \pm 6.65\end{array}$ & $\begin{array}{l}30.34 \pm 6.65 \\
36.04 \pm 6.71\end{array}$ & $\begin{array}{l}-1.56 \\
-4.30^{*}\end{array}$ & 0.09 \\
\hline SPPB (score) & $\begin{array}{l}\text { Control } \\
\text { Exercise }\end{array}$ & $\begin{array}{l}12.00 \pm 0.00 \\
11.50 \pm 0.85\end{array}$ & $\begin{array}{l}11.80 \pm 0.63 \\
11.80 \pm 0.63\end{array}$ & $\begin{array}{c}-1.67 \\
2.61\end{array}$ & 0.11 \\
\hline Timed up and go (sec) & $\begin{array}{l}\text { Control } \\
\text { Exercise }\end{array}$ & $\begin{array}{l}5.87 \pm 1.03 \\
6.02 \pm 1.12\end{array}$ & $\begin{array}{l}5.80 \pm 0.91 \\
5.79 \pm 0.94\end{array}$ & $\begin{array}{l}-1.18 \\
-3.85\end{array}$ & 0.54 \\
\hline Right grip strength $(\mathrm{kg})$ & $\begin{array}{l}\text { Control } \\
\text { Exercise }\end{array}$ & $\begin{array}{l}23.02 \pm 3.29 \\
24.04 \pm 5.49\end{array}$ & $\begin{array}{l}23.10 \pm 3.87 \\
24.20 \pm 5.86\end{array}$ & $\begin{array}{l}0.37 \\
0.67\end{array}$ & 0.93 \\
\hline Left grip strength $(\mathrm{kg})$ & $\begin{array}{l}\text { Control } \\
\text { Exercise }\end{array}$ & $\begin{array}{l}20.41 \pm 3.33 \\
21.83 \pm 5.93\end{array}$ & $\begin{array}{l}20.38 \pm 3.51 \\
21.62 \pm 7.63\end{array}$ & $\begin{array}{l}-0.15 \\
-0.94\end{array}$ & 0.89 \\
\hline
\end{tabular}

Notes: Values are in terms of mean \pm SD. *Significantly different from pre-intervention and post-intervention: $P<0.05$, ${ }^{\dagger}$ Significantly different from group and time: $P<0.05$. Abbreviation: SPPB, Short Physical Performance Battery.

a comparison of the two groups' body compositions before and after intervention via the multicomponent program, the mean skeletal muscle mass of the exercise group increased statistically significantly compared to that of the control group. Moreover, the average time measured for the SPPB gait-speed test was reduced from $4.51 \mathrm{~s}$ to $4.32 \mathrm{~s}$ for the exercise group. Meanwhile, a decrease in time was also measured for the TUG gait-speed test, from

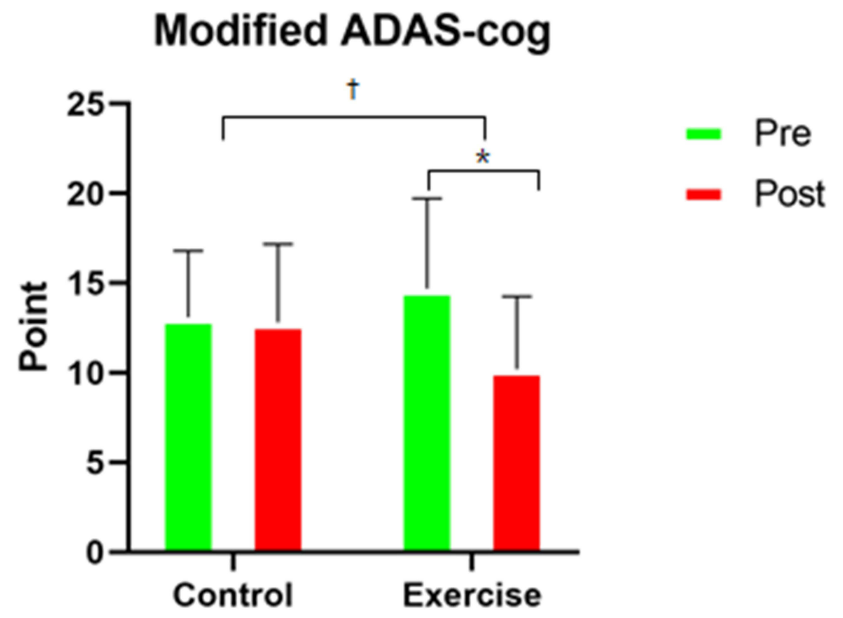

Figure 3 Changes in modified ADAS-Cog score at 12 weeks between control and exercise groups. *Significant difference between pre-intervention and post-intervention $(\mathrm{P}<.05)$; †Significant difference between time-by-group $(\mathrm{P}<.05)$.
$6.02 \mathrm{~s}$ to $5.79 \mathrm{~s}$, but no statistically significant difference was exhibited.

According to a previous study, the application of various multicomponent programs covering several aspects of physical and mental health, including aerobic and muscular exercises, working memory, calculation, attention concentration, spatial memory, self-control, and planning, on older adults for 12 weeks has been effective in improving their measures of physical function, such as dynamic balance. ${ }^{17}$ In a study that organized aerobic exercise programs thrice a week for four weeks, endurance and cognitive task performance significantly improved. ${ }^{34}$ In this study, the lower-limb pedaling exercise on the VR bicycle device improved gait speed and balance ability by strengthening the thigh muscles, contributing to falling prevention and calf muscles, which helps with positioning. It is believed that a significant increase in skeletal muscle mass owing to the application of a multicomponent program improves physical function and positively impacts the bodily functions of mobility, coordination, and balance.

A study involving 24 weeks of a multicomponent exercise intervention on older adults with dementia showed significant improvement in measures of participants' physical function, such as lower-limb flexibility, muscle 
Table 3 Changes in Measurements of Cognitive Functions at Baseline and After 12 Weeks for Exercise and Control Groups

\begin{tabular}{|c|c|c|c|c|c|}
\hline $\begin{array}{l}\text { Variables } \\
\text { Modified ADAS-Cog (score) }\end{array}$ & $\begin{array}{l}\text { Group } \\
\text { Control } \\
\text { Exercise }\end{array}$ & $\begin{array}{c}\text { Pre } \\
13.10 \pm 3.70 \\
14.70 \pm 5.0 \mid\end{array}$ & $\begin{array}{c}\text { Post } \\
12.80 \pm 4.37 \\
10.20 \pm 4.05\end{array}$ & $\begin{array}{l}\text { \%diff } \\
-2.29 \\
3.6 I^{*}\end{array}$ & $\begin{array}{c}P \\
0.01+\end{array}$ \\
\hline K-MMSE (score) & $\begin{array}{l}\text { Control } \\
\text { Exercise }\end{array}$ & $\begin{array}{l}26.80 \pm 1.69 \\
26.30 \pm 2.11\end{array}$ & $\begin{array}{l}27.00 \pm 2.31 \\
26.50 \pm 2.32\end{array}$ & $\begin{array}{l}0.75 \\
0.76\end{array}$ & 1.00 \\
\hline Digit span F+B (score) & $\begin{array}{l}\text { Control } \\
\text { Exercise }\end{array}$ & $\begin{array}{l}10.00 \pm 2.40 \\
9.60 \pm 2.01\end{array}$ & $\begin{array}{l}9.60 \pm 2.72 \\
9.30 \pm 2.79\end{array}$ & $\begin{array}{l}-4.00 \\
-3.12\end{array}$ & 0.87 \\
\hline COWAT animal (score) & $\begin{array}{l}\text { Control } \\
\text { Exercise }\end{array}$ & $\begin{array}{l}15.30 \pm 3.43 \\
14.60 \pm 3.44\end{array}$ & $\begin{array}{l}15.50 \pm 4.12 \\
12.80 \pm 3.82\end{array}$ & $\begin{array}{c}1.31 \\
-12.33\end{array}$ & 0.24 \\
\hline 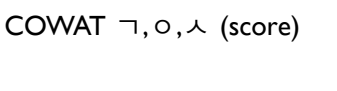 & $\begin{array}{l}\text { Control } \\
\text { Exercise }\end{array}$ & $\begin{array}{l}26.60 \pm 9.82 \\
21.90 \pm 7.40\end{array}$ & $\begin{array}{c}31.10 \pm 13.25 \\
25.20 \pm 7.44\end{array}$ & $\begin{array}{l}16.92 \\
15.07\end{array}$ & 0.65 \\
\hline Digit Symbol (score) & $\begin{array}{l}\text { Control } \\
\text { Exercise }\end{array}$ & $\begin{array}{l}49.70 \pm 18.04 \\
39.20 \pm 11.75\end{array}$ & $\begin{array}{l}53.40 \pm 20.72 \\
43.50 \pm 14.01\end{array}$ & $\begin{array}{c}7.44 \\
10.97^{*}\end{array}$ & 0.77 \\
\hline Stroop word (score) & $\begin{array}{l}\text { Control } \\
\text { Exercise }\end{array}$ & $\begin{array}{l}110.80 \pm 1.69 \\
111.30 \pm 1.34\end{array}$ & $\begin{array}{l}109.70 \pm 5.58 \\
\mid 11.00 \pm 2.31\end{array}$ & $\begin{array}{l}-0.99 \\
-0.27\end{array}$ & 0.64 \\
\hline Stroop color (score) & $\begin{array}{l}\text { Control } \\
\text { Exercise }\end{array}$ & $\begin{array}{l}95.70 \pm 22.16 \\
94.00 \pm 17.49\end{array}$ & $\begin{array}{l}96.80 \pm 22.63 \\
93.70 \pm 22.35\end{array}$ & $\begin{array}{c}1.15 \\
-0.32\end{array}$ & 0.70 \\
\hline SGDS-K (score) & $\begin{array}{l}\text { Control } \\
\text { Exercise }\end{array}$ & $\begin{array}{l}2.90 \pm 2.42 \\
3.80 \pm 3.19\end{array}$ & $\begin{array}{l}2.00 \pm 2.75 \\
2.60 \pm 3.27\end{array}$ & $\begin{array}{l}-31.03 \\
-31.58\end{array}$ & 0.87 \\
\hline
\end{tabular}

Notes: Values are in terms of mean \pm SD. *Significantly different from pre-intervention and post-intervention: $P<0.05$, ${ }^{\dagger}$ Significantly different from group and time: $P<0.05$. Abbreviations: Modified ADAS-cog, Modified Alzheimer's disease assessment scale-Cognitive subscale; K-MMSE, Korean mini-mental state examination; Digit span F+B, Digit span test forward/backward; COWAT, Controlled oral word association test; DSC, Digit symbol coding; Stroop, Korean-color word Stroop test; SGDS-K, Korean version of geriatric depression scale-short form.

strength, brachial-muscle strength, dynamic balance, and mobility. ${ }^{8}$ The multicomponent program promoted local and global muscles' movement through the upper limbs' functional motion, resulting in improved upper-limb and balance functions for the exercise group. ${ }^{19}$ In this study, cognitive training activities, such as arithmetic operations, fruit picking, and puzzle-solving, required the upper limbs' movement. This is considered to have improved the participants' skeletal muscle masses and positively affected their upper-limb and balance functions.

Regarding cognitive functions before and after intervention via the multicomponent program, the ADASCog scores for the exercise group were statistically significantly reduced compared to those for the control group. In a previous study, after 24 sessions of a multiinterim cognitive training program were implemented on normal older adults for eight weeks, their overall cognitive functions were improved based on examining the program's impact on cognitive and cerebral functions. In particular, their recognition abilities were considerably improved, as demonstrated in tasks relevant to working memory and episodic memory. ${ }^{35}$ In this study, the cognitive function evaluation's average score, or the modified ADAS-Cog, decreased from 5.50 to 4.40 for Word Recall and from 5.70 to 3.50 for Word Delayed Recall. In particular, the cognitive improvement between the two groups in terms of modified ADAS-Cog was significant for Word Recognition: the exercise group's average score decreased from 2.10 to 1.20 , whereas it increased from 1.80 to 2.90 for the control group. In this program, the VR bicycle ride stimulated memory through recall training in reminiscing places relevant to memories.

Conversely, the multicomponent training activities related to cognitive functions, such as arithmetic operations, fruit picking, and puzzle matching, significantly improved cognitive function. A study conducted on a long-term exercise program for older adults, atrophy of the frontal and temporal lobes, specifically, atrophy of the hippocampus, was reported to have slowed down due to the program, which significantly enhanced memory functions. ${ }^{36}$ In particular, attention and memory have been reported to increase by implementing computerbased multicomponent rehabilitation training. ${ }^{37}$ 
Furthermore, in this study, applying a multicomponent program has been demonstrated to improve cognitive function significantly.

However, SGDS-K, which evaluates depression, exhibited no significant difference. However, the exercise group's average SGDS-K score decreased from 3.8 to 2.6, whereas evaluation of compliance with the program measured a $95 \%$ engagement rate. This high engagement rate indicates a positive effect on depression reduction; the program is shown to induce older adults' interest and encourage positive response and active participation. Moreover, a previous review reported that ICT tools could be used as a lifestyle in older adults to improve life quality. Further, the use of ICT in the daily life of caregivers can help them understand the disease process and manage situations in a way that is beneficial for both parties. It is expected that future developments concerning technological projects can support this group of people. ${ }^{38,39}$

\section{Limitations}

Several limitations should be considered in this study. First, a multicomponent program has a higher proportion of cognitive programs than physical exercises and therefore has less effect on improving bodily functions than enhancing cognitive functions. Accordingly, future research on guidelines for proper exercise intensity and follow-ups to inspect the continuation of the effect after completion of intervention will be required. Second, more females than males were recruited in the present study. Thus, data interpretation needs to be cautious. Third, short intervention duration (12 weeks) and different program timing would also be the limitations of this study. Finally, multicenter clinical studies should also be conducted because the sample size in this study was relatively small. Moreover, studies with larger sample sizes should be conducted to identify the effectiveness of the multicomponent program. Nevertheless, this study has strengths in terms of an RCT design and standard test to provide reliable evidence.

\section{Conclusion}

It can be difficult to be engaged in a simple repetitive exercise program. Therefore, to meet the interest and expectations of older adults, a customized ICT-based multicomponent program, which can improve body composition and cognitive function in older adults and is believed to help prevent dementia, is recommended.

\section{Acknowledgments}

This research was supported by a grant of the Korea Health Technology R\&D Project through the Korea Health Industry Development Institute (KHIDI), funded by the Ministry of Health \& Welfare, Republic of Korea (grant number: HI15C1529).

\section{Disclosure}

The authors declare no conflict of interest.

\section{References}

1. Statistics Korea. 2019 the estimate of the future population; 2019.

2. Kim S, Won Y-S, Park H-K. The application of exercise program and the improvements for prevention and treatment of dementia. J Korean Assoc Phy Edu Sport Girls Women. 2017;31(3):131-152. doi:10.16915/jkapesgw.2017.09.31.3.131

3. Ma C-L, Ma X-T, Wang -J-J, et al. Physical exercise induces hippocampal neurogenesis and prevents cognitive decline. Behav Brain Res. 2017;317:332-339. doi:10.1016/j.bbr.2016.09.067

4. Teri L, McCurry SM, Buchner DM, et al. Exercise and activity level in Alzheimer's disease: a potential treatment focus. $J$ Rehabil Res Dev. 1998;35(4):411-419.

5. Colcombe SJ, Erickson KI, Scalf PE, et al. Aerobic exercise training increases brain volume in aging humans. J Gerontol a Biol Sci Med Sci. 2006;61(11):1166-1170. doi:10.1093/gerona/61.11.1166

6. Erickson KI, Voss MW, Prakash RS, et al. Exercise training increases size of hippocampus and improves memory. Proc Nat Acad Sci. 2011;108(7):3017-3022. doi:10.1073/pnas.1015950108

7. Duchesne C, Lungu O, Nadeau A, et al. Enhancing both motor and cognitive functioning in Parkinson's disease: aerobic exercise as a rehabilitative intervention. Brain Cogn. 2015;99:68-77. PMID: 26263381. doi:10.1016/j.bandc.2015.07.005

8. Hong S-Y. Effects of multi-component exercise and retraining after detraining on functional fitness and cognitive function in elder people with mild dementia. Korean J Health Promotion. 2014;14(1):33-42. doi:10.15384/kjhp.2014.14.1.33

9. Spirduso WW, Francis KL, MacRae PG. Physical dimensions of aging. 1995. Human Kinetics. Champaign. Illinois. USA.

10. Lee K. The effect of low extremity strengthening enhanced gait mat training on unstable surface on gait parameter and low extremity strength in elderly. J Special Edu Rehabi Sci. 2011;50(4):419-435.

11. Tiedemann A, Shimada H, Sherrington C, et al. The comparative ability of eight functional mobility tests for predicting falls in community-dwelling older people. Age Ageing. 2008;37 (4):430-435. doi:10.1093/ageing/afn100 PMID: 18487264.

12. Yoon J, Ahn H. A study on a sporting equipment developing to induce old people's interest. J Korean Soc Design Culture. 2012;18 (1):221-234.

13. Jung K. National Survey of the Elderly, Ministry of Health and Welfare, Korea Institute for Health and Social Affairs. Sejong; 2017.

14. Kim M, Cho S. The effect of the regular dance sports program on physiological function, mental health and perceived health state in older women. J Coaching Dev. 2004;6(3):281-290.

15. Santos GD, Nunes PV, Stella F, et al. Multidisciplinary rehabilitation program: effects of a multimodal intervention for patients with Alzheimer's disease and cognitive impairment without dementia. Arch Clin Psyc. 2015;42(6):153-156. doi:10.1590/0101-60830000000066

16. Chong B-H. The effect of cognitive occupational therapy in community living elders with mild cognitive impairment and dementia. $J$ Digital Convergence. 2013;11(3):317-325. doi:10.14400/ JDPM.2013.11.3.317 
17. Park J, Lee G, Woo M. The effect of cognitive-physical activity program on cognitive function in old adults. J Korean Phy Edu Assoc Girls Women. 2019;33(1):71-88. doi:10.16915/jkapesgw.2 019.3.33.1.71

18. Arkin S. Language-enriched exercise plus socialization slows cognitive decline in Alzheimer's disease. Am J Alzheimer's Dis Other Dementias. 2007;22(1):62-77. doi:10.1177/1533317506295377 PMID: 17534004.

19. Joo E, Bang Y. The effects of multimodal activity program on physical function, cognitive function and depression of the elderly stroke. J Korea Entertain Industry Assoc. 2018;12(7):317-328. doi:10.21184/jkeia.2018.10.12.7.317

20. Schaubert KL, Bohannon RW. Reliability and validity of three strength measures obtained from community-dwelling elderly persons. $J$ Strength Condition Res. 2005;19(3):717-720. doi:10.1519/R-15954.1 PMID: 16095431.

21. Kwon T. Effect on lower limb exercise using cycle ergometer on supine position. Proc Korean Soc Precision Eng Conf. 2011;1403-1404.

22. Abichou K, La, Corte V, Piolino P. Does virtual reality have a future for the study of episodic memory in aging? Geriatr Psychol Neuropsychiatr Vieil. 2017;15:65-74. doi:10.1684/pnv.2016.0648

23. Guralnik JM, Ferrucci L, Pieper CF, et al. Lower extremity function and subsequent disability: consistency across studies, predictive models, and value of gait speed alone compared with the short physical performance battery. J Gerontol a Biol Sci Med Sci. 2000;55(4): M221-M231. doi:10.1093/gerona/55.4.m221 PMID: 10811152.

24. Podsiadlo D, Richardson S. The timed "Up \& Go": a test of basic functional mobility for frail elderly persons. $\mathrm{J}$ Am Geriatr Soc. 1991;39(2):142-148. doi:10.1111/j.1532-5415.1991.tb01616.x PMID: 1991946

25. Rosen WG, Mohs RC, Davis KL. A new rating scale for Alzheimer's disease. Am J Psychiatry. 1984;141(11):1356-1364. doi:10.1176/ ajp.141.11.1356 PMID: 6496779.

26. Kang Y, Na DL, Hahn S. A validity study on the Korean Mini-Mental State Examination (K-MMSE) in dementia patients. J Korean Neurol Assoc. 1997;15(2):300-308.

27. Folstein MF, Folstein SE, McHugh PR. "Mini-mental state": a practical method for grading the cognitive state of patients for the clinician. J Psychiatr Res. 1975;12(3):189-198. doi:10.1016/00223956(75)90026-6 PMID: 1202204.
28. Yeom T. A Manual for Korean Wechsler Adult Intelligence Scale (K-WAIS). Seoul: Korean Guidance; 1992.

29. Kang Y. Controlled oral word association test in the elderly. Korean J Clin Psychol. 2000;19(2):385-392.

30. Benton AL. Differential behavioral effects in frontal lobe disease. Neuropsychologia. 1968;6(1):53-60. doi:10.1016/0028-3932(68) 90038-9

31. Kang Y, Jang S, Na D. Seoul Neuropsychological Screening Battery (SNSB-II). Incheon: Human Brain R\&C; 2012.

32. Cho MJ. Validation of geriatric depression scale, Korean version (GDS) in the assessment of DSM-III-R major depression. J Korean Neuropsyc Assoc. 1999;38(1):48-63.

33. Yesavage JA, Brink TL, Rose TL, et al. Development and validation of a geriatric depression screening scale: a preliminary report. J Psychiatr Res. 1982;17(1):37-49. doi:10.1016/0022-3956(82) 90033-4 PMID: 7183759.

34. Dustman RE, Ruhling RO, Russell EM, et al. Aerobic exercise training and improved neuropsychological function of older individuals. Neurobiol Aging. 1984;5(1):35-42. doi:10.1016/01974580(84)90083-6 PMID: 6738784.

35. Kim H. Effects of Cognitive Control Training on Brain Function in Older Adults. Seoul National University; 2012.

36. Shin E. Age-related neurocognitive changes and exercise-induced benefits: a review of cognitive neuroscientific research. Korean J Cognitive Sci. 2013;24(1):1-24. doi:10.19066/cogsci.2013.24.1.001

37. Oh BH. The effects of cognitive rehabilitation training on cognitive function of elderly dementia patients. J Korean Neuropsyc Assoc. 2003;42(4):514-519.

38. Claudia, Martínez-Alcalá I. Information and communication technologies in the care of the elderly: systematic review of applications aimed at patients with dementia and caregivers. JMIR Rehabil Assistive Technol. 2016;3(1):e6. doi:10.2196/rehab.5226

39. Knapova. L, Klocek. A, Elavsky. S. The role of psychological factors in older adults' readiness to use ehealth technology: cross-Sectional Questionnaire Study. J Med Internet Res. 2020;22(5):e14670. doi:10.2196/14670CIA_A_306894\#
Clinical Interventions in Aging

\section{Publish your work in this journal}

Clinical Interventions in Aging is an international, peer-reviewed journal focusing on evidence-based reports on the value or lack thereof of treatments intended to prevent or delay the onset of maladaptive correlates of aging in human beings. This journal is indexed on PubMed Central, MedLine, CAS, Scopus and the Elsevier

\section{Dovepress}

Bibliographic databases. The manuscript management system is completely online and includes a very quick and fair peer-review system, which is all easy to use. Visit http://www.dovepress.com/ testimonials.php to read real quotes from published authors. 